UDC 332; DOI 10.18551/rjoas.2022-01.05

\title{
UNDERSTANDING NETFLIX SUBSCRIPTION INTENTIONS USING TECHNOLOGY ACCEPTANCE MODEL: A STUDY IN DENPASAR
}

\author{
Wiradarma I Gusti Nyoman*, Piartrini Putu Saroyini \\ Faculty of Economics and Business, University of Udayana, Bali, Indonesia \\ *E-mail: okawiradarma@gmail.com \\ ORCID: 0000-0002-5045-4495
}

\begin{abstract}
Using the Technology Acceptance Model (TAM), this study aims to examine and explain the IS to Netflix in Denpasar, specifically the role of attitude (AT) in mediating the effect of perceived usefulness (PU) and perceived ease of use (PE) on the intention to subscribe (IS). This is an associative quantitative study conducted in Denpasar, Bali. The sample methodology utilized is a non-probability sampling technique known as purposive sampling. The data set consists of 182 samples obtained through the distribution of questionnaires with open and closed questions and statements that have been evaluated for validity and reliability. The analytical technique employed is the Structural Equation Model (SEM) with SmartPLS 3.3.3 software as an analytical tool. According to the findings of this study, PU and PE have a positive and significant influence on AT and IS, and AT has a positive influence on IS as well as partially mediating the relationship between PU and PE towards the IS. This study contribute to the advancement of marketing management science concerning the TAM theory. According to the research findings, the AT variable has the highest path coefficient, thus it may be used as a reference for Netflix when developing marketing strategies and communications to enhance someone's IS by cultivating a good AT toward the community.
\end{abstract}

\section{KEY WORDS}

Netflix, intention to subscribe, perceived usefulness, perceived ease of use, attitude.

Technology, which is developing more and more rapidly every time, is something that cannot be avoided, not least for various sectors of the business industry. Increasingly sophisticated technology is driving the industrial revolution which also brings new opportunities and threats to business, known as the Industrial Revolution 4.0. The transformation that can be felt is digitalization, namely the use of digital technology to change business models, one of which occurs in the entertainment industry. Aside from technological advancements, the Covid-19 pandemic situation that has occurred to date has also prompted companies to change their business models, which necessitates companies looking for alternatives or identifying ways to safely deliver their products and services while minimizing physical contact. (Seetharaman, 2021). While many corporate performances have declined since the epidemic, businesses in the digital entertainment industry have seen a surge in sales and earnings (Saleh, 2020).

Changes in media consumption in terms of facilities, patterns, and quality have occurred from advances in information and communication technology (Shim \& Kim, 2018). Broadband networks and smart gadgets, for example, are encouraging the growth of overthe-top (OTT) services (Kim et al., 2017). One of the most popular OTT services is Netflix. Netflix is a subscription-based digital streaming service provider (subscription video on demand / SVOD) that provides services for watching a big selection of movies and TV series in over 190 countries (netflix.com, 2021). Netflix can be accessed via smartphones, laptops, tablets, and smart TVs. Netflix has risen from its early roots as a DVD rental business and became one of the most notable online streaming services in the world. The company was among the first to acknowledge the opportunities of video streaming technology and started switching to the SVOD model in 2007. Netflix has developed significantly from 1997 to the present, making it an industry pioneer and market leader (statista.com, 2020). 
The popularity of the Netflix digital streaming service is also evidenced by the number of subscribers around the world. Based on data from the FIPP Global Digital Subscription Snapshot, Netflix has a subscriber base of 151.6 million subscribers. This shows that Netflix is the SVOD service with the largest number of subscribers worldwide. Netflix beat other global and regional brands such as iQiyi, Tencent Video, and Youku, which are SVOD platforms based in China, and Amazon Prime Video, which is a global competitor with only about half of Netflix's subscribers. According to Statista's research in September 2019 showing four SVOD brands with a global base, it is estimated that in 2024, Netflix will remain to be the global leader in SVOD services, with a global share of 23 percent, followed by Amazon Prime Video, which accounts for 13 percent of estimated worldwide SVOD subscriptions, and Disney's new streaming platform, Disney+, which will have an 8 percent share in the market.Meanwhile, according to research firm Media Partners Asia (MPA) which shows the top 4 platforms that accounted for 83 percent of the total customer base in Indonesia in early 2021, Netflix only has 850,000 users, far behind Disney+ Hotstar's paid users who dominate with a total of 2,5 million paid subscribers, Viu came in second with 1.5 million subscribers, and Vidio came in third with 1.1 million. (media-partners-asia.com, 2021).

In terms of means, patterns, and quality, technology alters how consumers consume media (Shim \& Kim, 2018). Consumption of broadcast media via digital and mobile technology is becoming more common, with consumers able to view movies, series, and shows online using digital streaming services on their devices, such as smartphones or tablets (Camilleri \& Falzon, 2021). These changes in consumer behavior in consuming media, particularly through the use of technology, have resulted in changes in consumer behavior in consuming media, so it is critical to understand how consumers intend to behave concerning a technology. The chance that customers will plan to take action against a product is referred to as behavioral intention, and it also refers to consumers' proclivity to take certain activities against a brand or product frequently (Porral and Mangin, 2017).

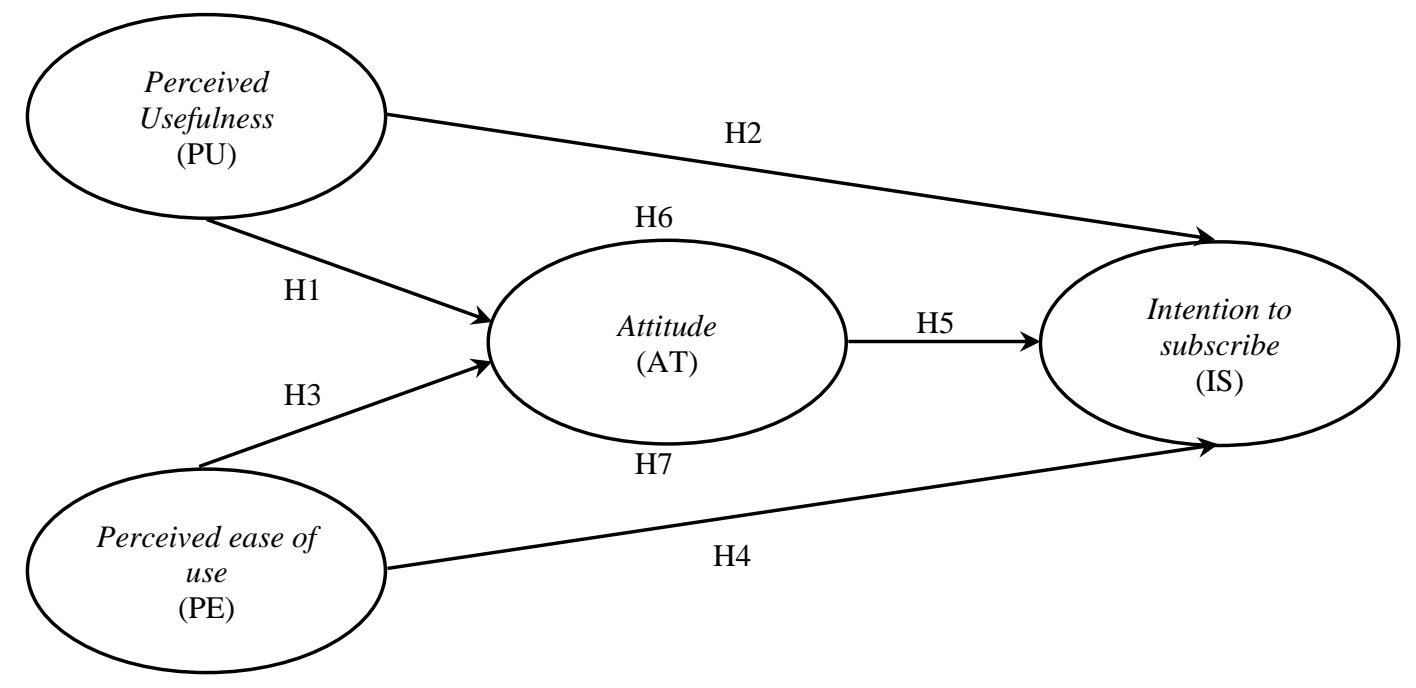

Figure 1 - Conceptual Framework

$\mathrm{H} 1$ : PU has a positive and significant effect on AT;

H2: PU has a positive and significant effect on the IS;

H3: PE has a positive and significant effect on AT;

H4: PE has a positive and significant effect on the IS;

H5: AT has a positive and significant effect on the IS;

H6: AT can significantly mediate the effect of PU on the IS;

H7: AT can significantly mediate the effect of PE on the IS.

In this study, IS refers to an individual's desire to subscribe to the Netflix streaming platform, in the sense that the individual is willing to pay for an account to use the service at the price offered. According to Davis et al. (1989), the TAM describes the elements that 
influence user acceptance of new information technology and systems. PU, PE, and AT are all factors that can improve behavioral intentions toward technology. PU is one of the elements that influence whether or not an individual adopts technology in terms of whether or not the individual perceives the usage of technology to help the goals that they wish to achieve (Camilleri \& Falzon, 2021). Individuals that have faith in a technology that provides benefits or may be used for their objectives would employ it. Similarly, if an individual believes that the technology does not serve its objective, they will not use it (Usman et al., 2020). The PE is another aspect that might impact an individual's acceptance of technology or a system. PE is a circumstance in which a person perceives that employing technology or information systems can stifle a person's efforts to accomplish a goal (Davis, 1989). The usage of a technology or information system should be devoid of physical and mental strain (Samudro \& Widyastytuti, 2020). When it comes to non-users, perceived simplicity of use can persuade them to consider utilizing a technology (Aslam et al., 2017).

\section{METHODS OF RESEARCH}

The design of this research is associative and causal research with quantitative methods. The sampling technique in this research is purposive sampling, the data collection technique is in the form of distributing questionnaires to respondents who are familiar with Netflix services in Denpasar City. The location of this research is in Denpasar City. As shown by records from the online publication Lokadata (2019), the islands of Java and Bali have the highest internet penetration, according to the 2018 BPS National Socio-Economic Survey, with Bali having a higher percentage of internet users than Java. Denpasar has the highest connectivity in the city. Since the internet is available to 68 percent of the population (Beritagar.id, 2019), it becomes an effective and efficient study location. The descriptive and inferential statistics were used to analyze the data for this study. In this study, the Structural Equation Model (SEM) method with the Partial Least Square (PLS) approach is used.

The PU variable research instrument was adapted from previous research, namely Davis (1989), Jegundo et al. (2020), Camilleri \& Falzon (2020), and Hu et al. (2019) with seven indicator items. The research instrument on the PE variable was adapted from previous research, namely Davis (1989), Jegundo et al. (2020), Kasilingam (2020), and Camilleri \& Falzon (2020) with seven indicator items. The research instrument on the AT variable was adapted from previous research, namely Belanche et al. (2020) and Khatimah \& Halim (2016) with five indicator items. The research instrument on the IS variable was adapted from previous research, namely Pereire \& Tam (2021) and Camilleri \& Falzon (2020) with five indicator items. Each indicator's measurement scale employs a 5-point Likert scale, ranging from 1 (strongly disagree) to 5 (strongly agree) (strongly agree). The convergent validity results showed that all indicators outer loadings have a value greater than 0.50 and a p-value less than 0.05 , and the Composite Reliability value and Cronbach's Alpha value for all constructs have a value of more than 0,6 so that all indicators have met the requirements of convergent validity and each research construct has good reliability.

\section{RESULTS AND DISCUSSION}

There were 182 people who participated in this study. Based on gender, respondents in this study had a fairly small difference, with slightly more women, namely 94 women when compared to 88 men. The majority of respondents are aged 17 to 24 years or Generation Z, with the last education being dominated by the undergraduate level. In terms of status or occupation, respondents in this study were dominated by respondents with private employee status, with the majority of respondents' monthly income being in the range of Rp 2 millionRp 5 million. The grouping of respondents based on their experience with watching movies, the majority of respondents spend 2 to 3 hours a week watching entertainment. When it comes to other known streaming platforms besides Netflix, the top 3 platforms that are known to the majority of respondents are the Vidio streaming platform with 54.9 percent, and Viu and Disney+ Hotstar each with 53.8 percent. The top 5 genres favored by respondents 
are Action (51.6 percent), Drama (51.1 percent), Comedy (47.3 percent), Romance (45.1 percent), and K-Drama (44.5 percent). Based on the comparison of the average scores based on the characteristics of the respondents, respondents who have watched paid films/videos have a higher average score than respondents who have never watched paid films/videos. Furthermore, respondents who have watched entertainment content provided by Netflix with friends/family/others have a higher average score that shows a difference from respondents who have never watched entertainment content provided by Netflix with friends/family/others.

Table 1 - Test Results of Direct Effects Between Variables

\begin{tabular}{lllll}
\hline Construct & Path Coefficient & T-statistics & P values & Result \\
\hline $\mathrm{PU} \rightarrow$ AT & 0,525 & 7.734 & 0,000 & Significant \\
\hline $\mathrm{PU} \rightarrow$ IS & 0,200 & 2.409 & 0,016 & Significant \\
\hline $\mathrm{PE} \rightarrow$ AT & 0,382 & 5.665 & 0,000 & Significant \\
\hline $\mathrm{PE} \rightarrow$ IS & 0,268 & 3.347 & 0,001 & Significant \\
\hline $\mathrm{AT} \rightarrow$ IS & 0,484 & 6.221 & 0,000 & Significant \\
\hline
\end{tabular}

PU has a positive and significant effect on AT, so $\mathrm{H} 1$ is accepted. This result is consistent with the assumptions of the TAM and is in line with previous research from Mwiya et al. (2017), Lee et al. (2017), and Liebana-Cabanillas et al. (2018). According to the findings of this study, the greater the PU of the Netflix streaming platform among the inhabitants of Denpasar City, the more favorable their AT toward subscribing to the Netflix streaming platform would be. Someone who believes that the Netflix streaming platform is useful for fulfilling his desire to consume entertainment content, particularly in terms of its effectiveness in accessing the desired entertainment, the quality of movies and TV series provided, the speed and ease of accessing entertainment, and being accessible regardless of place and time, will have a better AT, such as having a positive opinion, and believe that the decision to subscribe to the Netflix streaming platform is a good decision.

$\mathrm{PU}$ has a positive and significant effect on the IS, so H2 is accepted. This result is consistent with the assumptions of the TAM and is in line with previous research from Hansen et al. (2018), Ritonga et al. (2019), and Mutahar et al., (2018). According to the findings of this study, the greater the PU of the Netflix streaming platform among the inhabitants of Denpasar City, the greater their IS to the Netflix streaming platform. Someone who believes that the Netflix streaming platform is useful for fulfilling his desire to consume entertainment content, particularly in terms of its effectiveness in accessing the desired entertainment, the quality of movies and TV series provided, the speed and ease of accessing entertainment, and being accessible regardless of place or time, will have a growing preference and subscription intent towards the Netflix streaming platform, and this preference and subscription intent may grow.

PE has a positive and significant effect on AT, so H3 is accepted. This result is consistent with the assumptions of the TAM and is in line with previous research from Merwe \& Schalkwyk (2020), Kurniasari et al. (2019), and Pham et al. (2020). According to the findings of this study, the greater the PE of the Netflix streaming site by the people of Denpasar, the better their AT toward subscribing to the Netflix streaming platform would be. Someone who believes that the Netflix streaming platform will make it easier for them and does not require a lot of effort in terms of operating the application as a whole, such as a simple application, an easy-to-understand interface, the effort required to operate the platform, payment methods, and its compatibility on various devices, will have better ATs, such as having a positive opinion, and believe that the decision to subscribe to the Netflix streaming platform will make it easier for them.

PE has a positive and significant effect on the IS, so H4 is accepted. This result is consistent with the assumptions of the TAM and is in line with previous research from Rachmawati et al. (2020), Samudro \& Widyastytuti (2020), and Jin et al. (2020). According to the findings of this study, the greater the PE of the Netflix streaming platform by the inhabitants of Denpasar City, the greater their desire to subscribe to the Netflix streaming platform. Someone who believes that the Netflix streaming platform will make it easier for 
them and will not require a lot of effort in terms of operating the application as a whole, such as a simple application, an easy-to-understand interface, the effort required to operate the platform, payment methods, and its compatibility on various devices, will have an increasing preference and subscription intent towards the Netflix streaming platform.

AT has a positive and significant effect on the IS, so H5 is accepted. This result is consistent with the assumptions of the TAM and is in line with previous research from Kim \& Hwang (2020), Vuong et al. (2020), and Belanche et al. (2020). According to the findings of this study, the better Denpasar residents' ATs on subscribing to the Netflix streaming platform, the more likely they are to subscribe to the Netflix streaming platform. Someone with a positive AT, for example, who finds the decision to subscribe to the Netflix streaming platform amusing and useful, will have a higher preference and IS to the Netflix streaming platform, allowing for a continuing increase in subscription intentions.

Table 2 - Mediation Variable Test

\begin{tabular}{|c|c|c|c|c|c|}
\hline \multirow{2}{*}{ Variables } & \multicolumn{4}{|c|}{ Effect } & \multirow{2}{*}{ Result } \\
\hline & (A) & (B) & (C) & (D) & \\
\hline $\mathrm{PU} \rightarrow \mathrm{AT} \rightarrow \mathrm{IS}$ & $\begin{array}{l}0.254 \\
\text { (Sig.) }\end{array}$ & $\begin{array}{l}0,200 \\
\text { (Sig.) }\end{array}$ & $\begin{array}{l}0,525 \\
\text { (Sig.) }\end{array}$ & $\begin{array}{l}0,484 \\
\text { (Sig.) }\end{array}$ & Partial Mediation \\
\hline $\mathrm{PE} \rightarrow \mathrm{AT} \rightarrow \mathrm{IS}$ & $\begin{array}{l}0,185 \\
\text { (Sig.) }\end{array}$ & $\begin{array}{l}0,268 \\
\text { (Sig.) }\end{array}$ & $\begin{array}{l}0,382 \\
\text { (Sig.) }\end{array}$ & $\begin{array}{l}0,484 \\
\text { (Sig.) }\end{array}$ & Partial Mediation \\
\hline
\end{tabular}

Note: significance (Sig.) $=t$-statistic $>1.96$ at $a=5 \%$.

(A): the dependent variable's (IS) indirect effect on the independent variable (PU/PE).

$(B)$ : the independent variable's (PU/PE) direct effect on the dependent variable (IS).

$(C)$ : the independent variable's (PU/PE) direct effect on the mediating variable (AT).

(D): the mediating variable's (AT) direct effect on the dependent variable (IS).

Table 3 - Indirect Effect, Total Effect, and VAF Calculation

\begin{tabular}{lll}
\hline Variable & Indirect Effect & \\
\cline { 2 - 3 } & Coefficient Correlation & T-Statistics \\
\hline $\mathrm{PU} \rightarrow \mathrm{AT} \rightarrow \mathrm{IS}$ & $\mathbf{0 , 2 5 4}$ & 4.559 \\
\hline $\mathrm{PE} \rightarrow \mathrm{AT} \rightarrow \mathrm{IS}$ & $\mathbf{0 , 1 8 5}$ & 4.588 \\
\hline Variable & Total Effect & T-Statistics \\
\hline $\mathrm{PU} \rightarrow \mathrm{IS}$ & Correlation Coefficient & 7.035 \\
\hline $\mathrm{PE} \rightarrow \mathrm{IS}$ & $\mathbf{0 , 4 5 4}$ & 6.887 \\
\hline $\mathrm{PU} \rightarrow \mathrm{AT}$ & $\mathbf{0 , 4 5 2}$ & 7.734 \\
\hline $\mathrm{PE} \rightarrow \mathrm{AT}$ & 0,525 & 5.665 \\
\hline $\mathrm{AT} \rightarrow \mathrm{IS}$ & 0,382 & 6.221 \\
\hline $\mathrm{VAF} \rightarrow$ Indirect Effect/Total Effect $(0,254 / 0,454)$ & 0,484 & \\
\hline $\mathrm{VAF} \rightarrow$ Indirect Effect/Total Effect $(0,185 / 0,452)$ & 0,559 & \\
\hline
\end{tabular}

The results in this study indicate that $\mathrm{H} 6$ is accepted. This result is in line with previous research from Wu \& Chen (2017), Oentario et al. (2017), and Setyawati (2020). AT can partially mediate the relationship between PU and the IS to the Netflix streaming platform for the people of Denpasar City. Based on these results, it can be interpreted that although PU can generate an IS, the presence of an AT can help increase the IS to a higher level. This occurs because someone may have the intention of subscribing to the Netflix streaming platform because they have a perception or feel certain that the platform is effectively useful for fulfilling their desire to watch entertainment, and with a positive AT, they will undoubtedly be able to and further increase their IS to the Netflix streaming platform.

The results in this study indicate that $\mathrm{H} 7$ is accepted. This result is in line with previous research from Vahdat et al. (2020), Rehman \& Shaikh (2020), and Kasilingam (2020). AT can partially mediate the relationship between PE and the IS to the Netflix streaming platform for the people of Denpasar City. Based on these findings, it can be concluded that, while PE can induce an IS, the presence of an AT can aid boost the desire to subscribe. This occurs because someone may have the intention of subscribing to the Netflix streaming platform because they have a perception or feel confident that the platform will be easy to use and require little effort, and with a positive AT, they will most likely be able to and thus increase their IS to the Netflix streaming platform. 


\section{CONCLUSION AND SUGGESTIONS}

According to the findings of this study, PU and PE have a positive and significant influence on AT and IS, and AT has a positive influence on IS as well as partially mediating the relationship between PU and PE with the IS to the Netflix streaming platform in Denpasar City. Respondents' assessment of PU shows that the Netflix streaming platform has been trusted to provide a collection of films or TV series that have good quality. These results indicate that the good and consistent quality of entertainment provided by the Netflix streaming platform will be able to increase someone's IS. Moreover, respondents' assessment of PE shows that respondents believe that the Netflix streaming platform will be easy to use to access the entertainment they want. These results indicate that the belief in the ease of accessing the desired entertainment will attract potential consumers to subscribe to the Netflix streaming platform. The respondents' assessment of the AT variable shows that subscribing to the Netflix streaming platform is a fun idea. This explains that subscribing to the Netflix streaming platform can entertain and fulfill one's hedonic desires. In the end, companies engaged in streaming platform services, especially Netflix, need to consider the benefits and conveniences provided so that potential users have a positive AT to increase subscription intentions so that they can overcome competition problems and can take advantage of opportunities for increasing interest in digital entertainment platforms caused by the Covid pandemic at this time.

Suggestions that can be given based on the results of this research can be improved by the Netflix streaming platform. In terms of PU, what needs to be improved is the perception or belief that the Netflix streaming platform can be used at any time. The belief is that streaming movies on the Netflix platform will require a large cellular data and the assumption that although the content provided can be downloaded and watched offline, it requires preparation for the user, so it does not apply if the user wants to watch impulsively on certain occasions. Suggestions that can be done are to work with cellular data service providers, namely to provide special or additional quota packages that can be used for streaming movies. This also applies to the PE, namely the payment method provided by the Netflix streaming platform is still limited, by working with cellular data service providers, it is hoped that it will make it easier for consumers to make payments with the credit they have. In addition, the Netflix streaming platform can provide payment methods commonly used by the public, such as bank transfers or mobile banking, cooperate with more digital wallets and ecommerce, and apply vouchers or gift cards as Netflix has been implemented in other countries, which can be distributed in retail stores. Referring to the results of the comparative assessment based on the characteristics of the respondents, companies are also advised to consider offering a trial or limited free usage trial within a few days to attract potential customers so that the perception of the benefits and ease of use of the Netflix streaming platform is higher to increase their confidence to subscribe so that they can overcome competition issues and can take advantage of the opportunities for increasing interest in digital entertainment platforms caused by the current Covid-19 pandemic.

This study has limitations, such as the fact that the focus of this study is limited to the city of Denpasar, therefore its findings cannot be generalized to other regions. This research was only conducted at a specific time or in a cross-sectional manner, and because the social environment is dynamic, it is hoped that this research can be repeated in the future. This study is also limited to only investigating the TAM hypothesis, therefore it cannot investigate in-depth elements other than these variables, such as consumer external influences. Further research can look into the external factor that influences the IS.

\section{REFERENCES}

1. Aslam, W., Ham, M., \& Arif, I. (2017). Consumer behavioral intentions towards mobile payment services: An empirical analysis in Pakistan. Market-Trziste, 29(2), 161-176. 
2. Belanche, D., Flavián, M., \& Pérez-Rueda, A. (2020). Mobile Apps Use and WOM in the Food Delivery Sector: the Role of Planned Behavior, Perceived Security and Customer Lifestyle Compatibility. Sustainability (Switzerland), 12(10).

3. Beritagar.id. 2019. Penetrasi internet di Bali paling tinggi. Diakses dari https://beritagar.id/artikel/berita/penetrasi-internet-di-bali-paling-tinggi.

4. Camilleri, M. A., \& Falzon, L. (2021). Understanding Motivations to Use Online Streaming Services: Integrating the Technology Acceptance Model (Tam) and the Uses and Gratifications Theory (Ugt). Spanish Journal of Marketing - Esic, 25(2), 217-238.

5. Davis, F. D. (1989). Perceived usefulness, Perceived ease of use, and User Acceptance of Information Technology. MIS Quarterly, 13(3), 319-340.

6. Davis, F. D., Bagozzi, R. P., \& Warshaw, P. R. (1989). User acceptance of computer technology: A comparison of two theoretical models. Management Science, 35(8), 982-1003.

7. Hu, H., Zhang, D., \& Wang, C. (2019). Impact of social media influencers' endorsement on application adoption: A trust transfer perspective. Social Behavior and Personality, 47(11).

8. Jegundo, A. L., Dantas, C., Quintas, J., Dutra, J., Almeida, A. L., Caravau, H., Rosa, A. F., Martins, A. I., \& Rocha, N. P. (2020). Perceived Usefulness, Satisfaction, Ease of Use and Potential of a Virtual Companion to Support the Care Provision for Older Adults. Technologies, 8(3), 42.

9. Jin, C. C., Seong, L. C., \& Khin, A. A. (2020). Consumers' Behavioural Intention to Accept of the Mobile Wallet in Malaysia. Journal of Southwest Jiaotong University, 55(1).

10. Kasilingam, D. L. (2020). Understanding the Attitude and Intention to Use Smartphone Chatbots for Shopping. Technology in Society, 62.

11. Khatimah, H., \& Halim, F. (2016). the Effect of Attitude and Its Decomposed, Subjective Norm and It Decomposed on Intention to Use E-Money Server in Indonesia. Journal of Scientific Research and Development, 3(1), 21-32.

12. Kim, J. J., \& Hwang, J. (2020). Merging the Norm Activation Model and the Theory of Planned Behavior in the Context of Drone Food Delivery Services: Does the Level of Product Knowledge Really Matter? Journal of Hospitality and Tourism Management, $42,1-11$.

13. Kim, N., Chun, E., \& Ko, E. 2017. Country of origin effects on brand image, brand evaluation, and purchase intention: A closer look at Seoul, New York, and Paris fashion collection. International Marketing Review, 34(2), 254-271.

14. Liébana-Cabanillas, F., Higueras-Castillo, E., Molinillo, S., \& Ruiz Montañez, M. (2018). Assesing the Role of Risk and Trust in Consumers' Adoption of Online Payment Systems. International Journal of Information Systems and Software Engineering for Big Companies, 5(2), 99-113.

15. Lokadata. 2019. Penetrasi internet di Bali paling tinggi. Diakses dari https://lokadata.id/artikel/penetrasi-internet-di-bali-paling-tinggi.

16. Media Partners Asia. 2021. Indonesia: Cumulative SVOD subscribers reach 7 mil. Diakses dari https://www.media-partners-asia.com/article.php?id=2332.

17. Merwe, M. V. D. (2020). Perceived usefulness of Video and Music Streaming Services Among Generation Y Students. International Journal of Social Sciences and Humanity Studies, 12(2), 498-512.

18. Mwiya, B., Chikumbi, F., Shikaputo, C., Kabala, E., Kaulung'ombe, B., \& Siachinji, B. (2017). Examining Factors Influencing E-Banking Adoption: Evidence from Bank Customers in Zambia. American Journal of Industrial and Business Management, 07(06), 741-759.

19. Oentario, Y., Harianto, A., \& Irawati, J. (2017). Pengaruh Usefulness, Ease of use, Risk Terhadap Intentionto Buy Onlinepatisserie Melalui Consumer Attitude Berbasis Media Sosial Di Surabaya. Jurnal Manajemen Pemasaran, 11(1).

20. Pham, H. T., Hoang, K. T., Nguyen, T. T., Do, P. H., \& Mar, M. T. C. (2021). Sharing Economy: Generation Z's Intention Toward Online Fashion Rental in Vietnam. Journal of Asian Finance, Economics and Business, 8(3), 997-1007. 
21. Porral, C. C., \& Mangin, J. P. L. 2017. Store brands' purchase intention: Examining the role of perceived quality. European Research on Management and Business Economics, 23(2), 90-95.

22. Rachmawati, I. K., Bukhori, M., Nuryanti, F., Marta, D., \& Hidayatullah, S. (2020). The Effect of Perceived usefulness and Perceived ease of use on Online Buying Interest Is Through the Attitude of Using Social Media. ICGSS.

23. Rehman, Z. U., \& Shaikh, F. A. (2020). Critical Factors Influencing the Behavioral intention of Consumers Towards Mobile Banking in Malaysia. Technology \& Applied Science Research, 10(1).

24. Saleh, Y. 2020. ICT, social media and COVID-19: evidence from informal home-based business community in Kuwait City. Journal of Enterprising Communities: People and Places in the Global Economy.

25. Seetharaman, P. 2020. Business models shifts: Impact of Covid-19. International Journal of Information Management, 54, 1-4.

26. Setyawati, R. E. (2020). Pengaruh Perceived Usefullness, Perceived ease of use Terhadap Behavioral intention to Use Dengan Attittude Towards Using Sebagai Variabel Intervening (Studi Kasus Pada Gopay Dikota Yogyakarta). J. Ekobis Dewantara, 3(1).

27. Statista. (2020). Netflix - statistics \& facts. Diakses dari https://www.statista.com/topics/842/netflix.

28. Usman, O., Septianti, A., Susita, D., \& Marsofiyati. (2021). The Effect of Computer SelfEfficacy and Subjective Norm on the Perceived usefulness, Perceived ease of use and Behavioural Intention to Use Technology. Ibima Business Review, 2020.

29. Vahdat, A., Alizadeh, A., Quach, S., \& Hamelin, N. (2021). Would You Like to Shop Via Mobile App Technology? the Technology Acceptance Model, Social Factors and Purchase Intention. Australasian Marketing Journal, 29(2), 187-197.

30. Vuong, B. N., Hieu, V. T., \& Trang, N. T. T. (2020). An Empirical Analysis of Mobile Banking Adoption in Vietnam. Revista Eletrônica Gestão \& Sociedade, 14(37), 33653393.

31. Wu, B., \& Chen, X. (2017). Continuance Intention to Use Moocs: Integrating the Technology Acceptance Model (TAM) and Task Technology Fit (TTF) Model. Computers in Human Behavior, 67, 221-232. 